\title{
Effects of different of salt-reducing formulas on the quality characteristics of clam sausage
}

\author{
Ying BU ${ }^{1}$, Wenting $\mathrm{XU}^{1}$, Wenhui ZHU*1, Xuepeng LI ${ }^{1}$, Laijin $\mathrm{SU}^{2}$ \\ ${ }^{1}$ College of Food Science and Engineering, Bohai University, National \& Local Joint Engineering Research Center of Storage, \\ Processing and Safety Control Technology for Fresh Agricultural and Aquatic Products, Jinzhou 121103, China \\ ${ }^{2}$ Wenzhou Academy of Agricultural Science, Wenzhou Characteristic Food Resources Engineering and Technology Research Center, \\ Wenzhou 325006, China
}

\begin{abstract}
In this paper, Meretrix meretrix Linnaeus and Nemipterus virgatus surimi were used as raw materials, and the effects of different salt-reducing formulas on the characteristics of low-sodium clam meat sausage was studied. The results showed that there was not significantly different in texture properties (except T1) and gel properties among each groups, and the groups treated with $50 \% \mathrm{KCl}$ instead of $50 \%$ $\mathrm{NaCl}$ significantly decreased the sodium content. The addition of lysine, F1 (atmospheric clam enzymatic hydrolysate lyophilized powder), F2 (ultrahigh pressure clam enzymatic hydrolysate lyophilized powder) and MRPF1 (Maillard Reaction products of F1) increased the sensory acceptance, taste perception and decreased bitterness, astringency. On the premise of adding F1, F2 and MRPF1, it is feasible to add 50\% $\mathrm{KCl}$ instead of $50 \% \mathrm{NaCl}$ in clam sausage. The results demonstrated that adding MRPF1 can better improve people's salty perception, reduce the amount of sodium and increase delicate flavor in clam meat sausages.
\end{abstract}

\section{Introduction}

Salt plays an important role in product processing, flavor, texture and shelf life, especially in food processing $[1,2]$. At the same time, it is also a flavoring agent with important physiological functions. However, the daily intake of salt in human life is far higher than requirement [1]. High salt intake has been well documented to cause high blood pressure, cardiovascular disease and a variety of other diseases [3].

Generally, traditional meat sausages have a high salt content, how to reduce the amount of salt in processing has become a hot research topic. Moreover, umami peptide plays an important role in umami substances. Zhang et al. have been isolated and identified many umami peptides from fish protein hydrolysates and fish sauces [4, 5]. Many marine-derived proteins are the important sources of umami substances. Li et al. have been identified seven novel umami peptides from the aqueous extract of cooked Meretrix meretrix Linnaeus [6]. The Meretrix meretrix Linnaeus is one of the major economic marine-cultured bivalve species with delicious taste [7]. However, the effect of Meretrix meretrix Linnaeus extracts on salt-reducing and quality characteristics of shellfish sausage rarely reported.

Therefore, the objective of our work was to investigate the effects of Meretrix meretrix Linnaeus extracts on salt-reducing and quality characteristics of shellfish sausages. This study aims to provide a reference for the development of low-salt shellfish sausage products.

\section{Materials and methods}

\subsection{Preparation enzymatic hydrolysis of Meretrix meretrix Linnaeus muscle}

According to the results of our previous study, the enzyme/substrate (E/S) ratio was 4:1000, and the ratio of Flavourzyme $^{\mathrm{TM}} 500 \mathrm{MG}$ and Novozym ${ }^{\mathrm{TM}} 11039$ was 1:1. The enzymatic hydrolysis conditions were as follows: temperature $50^{\circ} \mathrm{C}$, liquid-solid ratio $1: 1$ and $\mathrm{pH}$ 7.0. The hydrolysis experiments were first carried out using ultrahigh-voltage equipment (HPP.L2-600/0.6, Huataisenmiao, Tianjin, China) for $1 \mathrm{~h}$ at $250 \mathrm{MPa}$, followed by atmospheric pressure hydrolysis for $4 \mathrm{~h}$. After that, the mixture kept at $100^{\circ} \mathrm{C}$ for $10 \mathrm{~min}$ to stop the reaction. The enzymatic hydrolysates were centrifuged in a refrigerated centrifuge (LYNX-4000; Thermo Fisher Co., USA) for $15 \mathrm{~min}\left(5120 \mathrm{~g}, 4^{\circ} \mathrm{C}\right)$, and the supernatant was lyophilized (Free Zone $2.5 \mathrm{~L}$; Labconco Co., USA) to obtain powder, referred to as F2; the sample prepared in accordance with the above preparation process without UHP treatment is referred to as F1.

\subsection{Preparation of Maillard Reaction products (MRPs)}

Corresponding author's e-mail: zhuwenhui@bhu.edu.cn,wenhuiby130@163.com 
A $10 \mathrm{~mL}$ solution reaction system ( $\mathrm{pH} 7.0)$ consisting of lyophilized powder $(0.50 \mathrm{~g})$, D-xylose $(0.20 \mathrm{~g})$ and $\mathrm{L}$ cysteine $(0.15 \mathrm{~g})$ were prepared in a tube. The tube was sealed and transferred into an oil bath at $120^{\circ} \mathrm{C}$ for $1.5 \mathrm{~h}$, and then cooled. The supernatant was lyophilized to obtain powder, referred to as MRPF1.

\subsection{Preparation of clam meat sausage}

The clam sausages of seven treatments were manufactured with different ingredients. Details are as follows: two control treatments (TC1 with $1.6 \% \mathrm{NaCl}$ and TC2 with $0.8 \% \mathrm{NaCl}, 0.8 \% \mathrm{KCl}, 1 \%$ Lysine and $0.06 \%$ Inosinate + Guanylate), the other five treatments $\mathrm{T} 1$ with $0.8 \% \mathrm{NaCl}$ and $0.8 \% \mathrm{KCl}, \mathrm{T} 2$ with $0.8 \% \mathrm{NaCl}, 0.8 \% \mathrm{KCl}$ and $1 \%$ Lysine, T3 with $0.8 \% \mathrm{NaCl}, 0.8 \% \mathrm{KCl}$ and $0.4 \%$ F1, T4 with $0.8 \% \mathrm{NaCl}, 0.8 \% \mathrm{KCl}$ and $0.2 \% \mathrm{~F} 2$, T5 with $0.8 \% \mathrm{NaCl}, 0.8 \% \mathrm{KCl}$ and $0.6 \% \mathrm{MRPF} 1$. Clam sausages were prepared with Meretrix meretrix Linnaeus meat (15\%), Nemipterus virgatus surimi $(45.9 \%)$, ice water $(15 \%)$, starch $(10 \%)$, pork fat $(7.5 \%)$, soy protein $(1.8 \%)$, vegetable oil $(1.2 \%)$, and carrageenan $(0.08 \%)$.

\subsection{Sensory evaluation}

The attributes of appearance, color, texture, flavor, taste and overall acceptability of clam sausage were evaluated by a panel of 30 untrained consumers. The casing was removed and the sausages were cut into slices of $4 \mathrm{~mm}$ thickness. Samples from each treatment were labeled with random, three-digit codes and presented on a plateat room temperature with distilled water to rinse mouth. Sensory evaluation was measured using 9-box hedonic scale (1extremely dislike-9 extremely like) [8].

\subsection{Determination of texture and gel properties}

The samples were cut into $2-3 \mathrm{~cm}$ cylinders as above treatment. Texture characteristics and gel strength were examined using a Model TA.XT.PLUS texture analyzer (Stable Micro System, UK). The measurement parameters were as follows: probe model (texture characteristics: $\mathrm{P} / 50$; gel strength: $\mathrm{P} / 5 \mathrm{~s}$ ), trigger force $5 \mathrm{~g}$, compression ratio $70 \%$, pre-test speed, test speed and post-test speed $1 \mathrm{~mm} / \mathrm{s}$.

\subsection{Analysis of electronic nose (e-nose) and electronic tongue (e- tongue)}

In accordance with the method of Huang et al. [9], we analyzed samples by an aportable e-nose system (PEN3, Win Muster Airsense Analytics Inc., Germany), and analyzed sensory characteristics of samples using etongue system (SA-402B, Insent, Japan). Four milliliter sample put into $100 \mathrm{~mL}$ capacity bottle and fixed constant volume with deionized water. The detailed information about the method was available from $\mathrm{Zhu}$ et al.[10].

\subsection{Statistical analysis}

The experimental data was analyzed by one-way analysis of variance (ANOVA) and Duncan procedure was used to reveal intergroup differences. Figures were obtained using OriginPro9 (Origin Lab Co., Northampton, MA, USA). The principal component analysis (PCA) was described by the WinMuster e-nose software. The data from the e-tongue were processed by self-contained systems.

\section{Results and discussion}

\subsection{Sensory evaluation}

The results of the sensory evaluation were presented in Fig 1. There was no significant difference in the appearance of clam sausages among the 7 groups, and there was no significant difference in color except T5. Compared with other treatments, T1 had the lowest sensory scores $(P<0.05)$ of flavor, taste and overall acceptability. This may be caused by the addition of $\mathrm{KCl}$, which brought metallic taste and bitter taste. However, lysine (TC2, T2), F1 (T3), F2 (T4) and MRPF1 (T5) together with $\mathrm{NaCl}$ and $\mathrm{KCl}$ increased the sensory acceptance of the treatments compared to the treatment $\mathrm{T} 1(0.8 \% \mathrm{NaCl}+0.8 \% \mathrm{KCl})$, it showed that lysine and $\mathrm{I}+\mathrm{G}$ can regulate the bad flavor brought by $\mathrm{KCl}[11,12]$. Meanwhile, the addition of F1, F2 and MRPF1 can also enhance the flavor of the clam sausages.

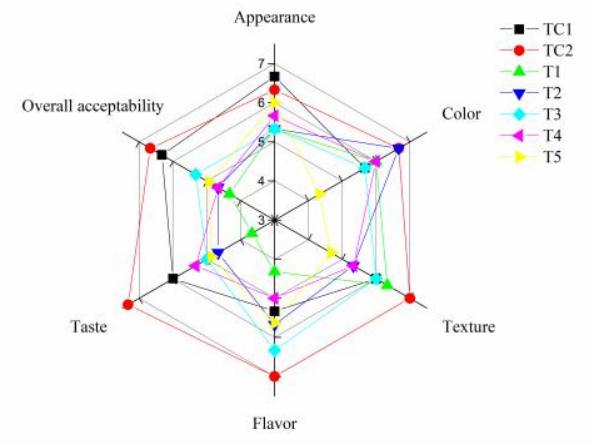

Figure 1: Sensory evaluation results of different treatments

\subsection{Gel properties}

As can been seen from Fig 2, none of the treatment set in the experiment had a significant effect $(P>0.05)$ on the gel properties of the clam sausages. The treatment TC2 $(0.8 \% \mathrm{NaCl}+0.8 \% \mathrm{KCl}+1 \%$ lysine $+0.06 \%(\mathrm{I}+\mathrm{G}))$ has the highest gel properties, which indicated that the addition of lysine contributed to the monomers formation of myosin in a low salt concentration solution, resulting in a fine gel properties [13, 14]. 


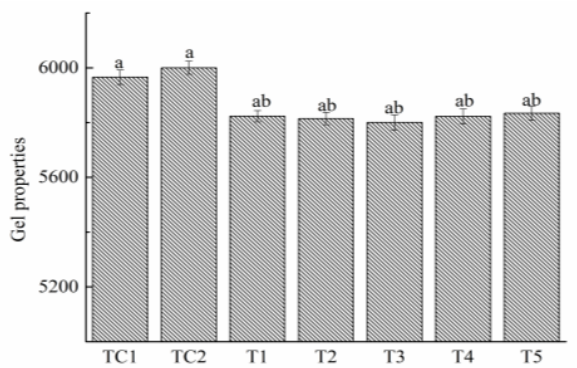

Figure 2: Gel properties and $\mathrm{pH}$ value of the different treatments

\subsection{The flavor characteristics and e-tongue analysis}

As shown in Table 1, a significant difference in the bitterness, saltiness and umami were exhibited $(P<0.05)$. In the case of $\mathrm{T} 4$, the sample showed a stronger bitter taste. For T1, the addition of the mixture not only made an intense in bitter, but reduced the saltiness and umami. The effects of the addition of $\mathrm{KCl}$ to the salted treatments were consistent with previous studies [15, 16]. The results of the flavor characteristics of e-tongue were in line with the sensory results. The saltiness of the groups treated with $\mathrm{KCl}$, lysine, F1, F2, MRPF1 were significantly lower than that of the control group (TC1). While the umami of the groups treated with lysine (T2), F1 (T3), F2 (T4), MRPF1 (T5) were increased than that of the $\mathrm{KCl}$ group (T1). The umami, richness of the addition of MRPF1 (T5) were higher than treated with lysine (T2), F1 (T3), F2 (T4). Therefore, the present results showed that there was possible to increase flavor and decrease sodium in the low sodium clam sausages by adding different clam extracts, and the addition of the MRPF1 (T5) could better improve umami, richness of the clam sausages.

Table 1: Analysis of electronic tongue taste of clam sausage in different treatment groups

\begin{tabular}{lllll}
\hline $\begin{array}{l}\text { Treatm } \\
\text { ent }\end{array}$ & Bitterness & Umami & Richness & Saltiness \\
\hline TC1 & $9.63 \pm 0.00 \mathrm{c}$ & $1.67 \pm 0.00 \mathrm{ab}$ & $0.26 \pm 0.00 \mathrm{a}$ & $-1.87 \pm 0.00 \mathrm{~b}$ \\
$\mathrm{TC} 2$ & $9.21 \pm 0.18 \mathrm{~d}$ & $1.84 \pm 0.13 \mathrm{a}$ & $0.26 \pm 0.12 \mathrm{a}$ & $-1.55 \pm 0.04 \mathrm{a}$ \\
$\mathrm{T} 1$ & $10.18 \pm 0.17 \mathrm{ab}$ & $1.33 \pm 0.04 \mathrm{~d}$ & $0.28 \pm 0.09 \mathrm{a}$ & $-2.55 \pm 0.05 \mathrm{f}$ \\
$\mathrm{T} 2$ & $9.59 \pm 0.14 \mathrm{c}$ & $1.45 \pm 0.06 \mathrm{~cd}$ & $0.09 \pm 0.11 \mathrm{a}$ & $-2.04 \pm 0.03 \mathrm{c}$ \\
$\mathrm{T} 3$ & $9.94 \pm 0.07 \mathrm{~b}$ & $1.62 \pm 0.07 \mathrm{~b}$ & $0.24 \pm 0.14 \mathrm{a}$ & $-2.16 \pm 0.05 \mathrm{~d}$ \\
$\mathrm{~T} 4$ & $10.27 \pm 0.02 \mathrm{a}$ & $1.55 \pm 0.09 \mathrm{bc}$ & $0.23 \pm 0.18 \mathrm{a}$ & $-2.23 \pm 0.05 \mathrm{e}$ \\
$\mathrm{T} 5$ & $9.44 \pm 0.23 \mathrm{~cd}$ & $1.68 \pm 0.08 \mathrm{ab}$ & $0.29 \pm 0.13 \mathrm{a}$ & $-2.15 \pm 0.04 \mathrm{~d}$ \\
\hline
\end{tabular}

The result of the PCA of e-tongue was shown in Fig 3. The principal components (PCs) PC1 and PC2 represented $64.86 \%$ and $32.89 \%$ of the total variance, respectively, with the cumulative contribution rate accounting for $97.75 \%$, which indicated they are sufficient to explain the total variance in the 7 groups [17]. In addition, it can be observed that the 7 groups clam sausages were clearly apparent in the bi-plot of PCA, with the TC1, TC2 and T5 samples located in the right of the $\mathrm{Y}$-axis and $\mathrm{T} 1, \mathrm{~T} 2, \mathrm{~T} 3$ and $\mathrm{T} 4$ in the left. Moreover, the sample of T5 tended to increase in the $\mathrm{Y}$ axis, it was indicated that the sample of T5 have a better flavor, which was consistent with the results of e-tongue flavor characteristics. Moreover, there was no overlap between them, which indicated that the PCA of the etongue can well distinguish the flavor characteristics of the 7 groups clam sausages.

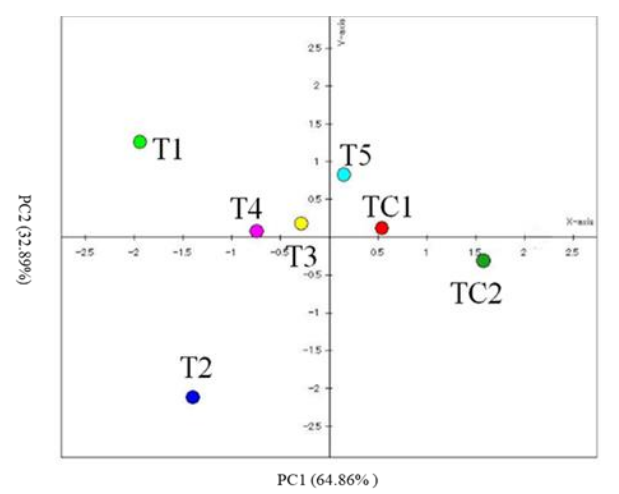

Figure 3: Principal component analysis (PCA) of electronic tongue in different treatment groups

\subsection{Texture profile}

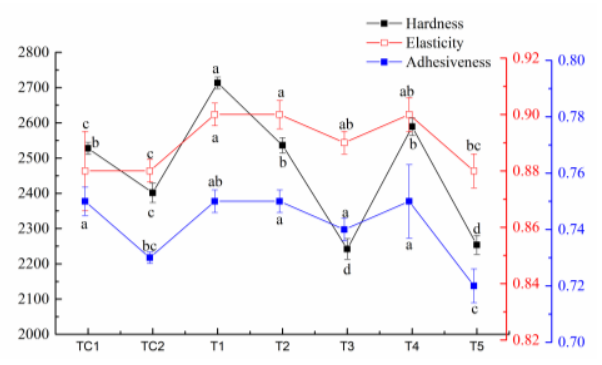

(a) The hardness, elasticity and adhesiveness

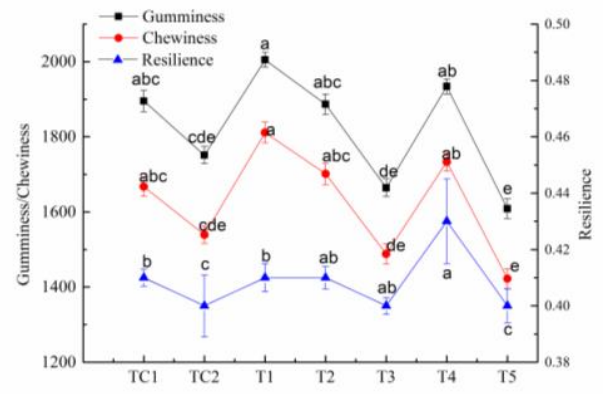

(b) The gumminess, chewiness and resilience

Figure 4: Texture property of clam sausages in different treatment groups

The texture property was presented in Fig 4. A significant difference in the hardness, gumminess and chewiness $(P$ $<0.05)$ were exhibited. The elasticity, gumminess and resilience values were $0.88 \sim 0.90,0.72 \sim 0.75$ and $0.40 \sim 0.43$ respectively in the 7 treatments. Compared with the other treatments, the hardness, gumminess and chewiness of $\mathrm{T} 1(0.8 \% \mathrm{NaCl}+0.8 \% \mathrm{KCl})$ were greatly increased. The reason for this change might be that the addition of the mixture increased the hardness of the 
sample. The results are consistent with several studies on salt reduction [18].

\subsection{E-nose analysis}

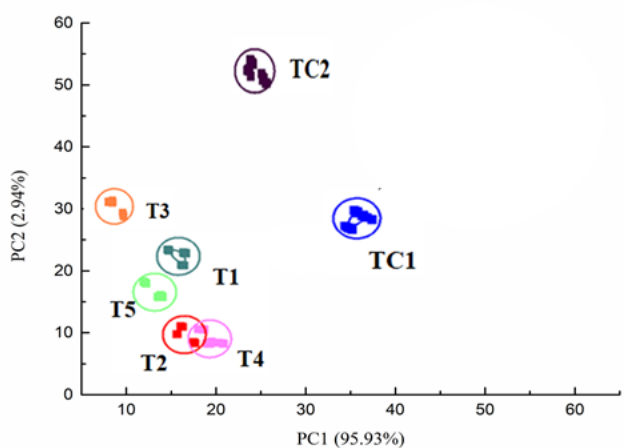

Figure 5: Principal component analysis (PCA) of electronic nose in different treatment groups

The PCA result of the e-nose was presented in Fig 5. The PC1 and PC2 represented $95.93 \%$ and $2.94 \%$ respectively, with the cumulative contribution rate accounting for $98.87 \%$. Therefore, it probably can better reflect all the original information of the 7 groups. There were some overlap between $\mathrm{T} 4(0.8 \% \mathrm{NaCl}+0.8 \% \mathrm{KCl}+0.2 \% \mathrm{~F} 2)$ and $\mathrm{T} 2(0.8 \% \mathrm{NaCl}+0.8 \% \mathrm{KCl}+1 \% \mathrm{Lys})$, which indicated that the flavors of two group were similar, and the distances were away from $\mathrm{TC} 1$, indicating that the odor of the clam sausages could be significantly distinguished with TC1 [19].

\section{Conclusion}

This experiment studied the effect of different of saltreducing formulas on the quality characteristics of clam sausage. Compared to the treatment group T1 $(0.8 \%$ $\mathrm{NaCl}+0.8 \% \mathrm{KCl}$ ), groups with lysine, F1, F2, MRPF1 exhibited delicate flavor and better sensory evaluation, and the T5 (MRPF1) showed higher salt perception, richness and lower bitterness than that of groups with lysine, F1, F2. When compared to the treatment group T1, there have a significant difference in all treatment groups of the mineral levels, which reduced sodium content and increased potassium content, so that could improve the umami taste and improve the perception of sodium in clam sausages.

\section{Acknowledgements}

The National Key Research and Development Program (No.2018YFD0400603) and Wenzhou Key Laboratory (Engineering Center) construction project (ZD202003) supported this study.

\section{References}

1. DESMOND E. 2006. Reducing salt: A challenge for the meat industry. Meat Science, 74(1), 188-196.
2. TIM H. 2002. Sodium technological functions of salt in the manufacturing of food and drink productions. British Food Journal, 104(2), 126-152.

3. AWAD T S, MOHARRAM H A, SHALTOUT O E, et al. 2012. Applications of ultrasound in analysis, processing and quality control of food: A review. Food Research International, 48(2), 410-427.

4. ZHANG M, WANG X L, ZHOU G, et al. 2012. Isolation and identification of flavour peptides from puffer fish (Takifugu obscurus) muscle using an electronic tongue and MALDI-TOF/TOF MS/MS. Food Chemistry, 135(3), 1463-1470.

5. ZHANG Y, VENKITASAMY C, PAN Z L, et al. 2017. Novel Umami Ingredients: Umami Peptides and Their Taste. Food Science, 82(1), 16-23.

6. LI X P, XIE X X, WANG J, et al. 2020. Identification, taste characteristics and molecular docking study of novel umami peptides derived from the aqueous extract of the clam Meretrix meretrix Linnaeus. Food Chemistry, 312, 126053.

7. WANG L, CHEN L, LI J, et al. 2018. Structural elucidation and immune-enhancing activity of peculiar polysaccharides fractioned from marine clam Meretrix meretrix (Linnaeus). Carbohydrate Polymers, 201, 500-513.

8. HORITA C N, FAR'IAS A M, BARBOSA T S, et al. 2016. The antimicrobial, antioxidant and sensory properties of garlic and its derivatives in Brazilian low-sodium frankfurters along shelf-life. Food Research International, 84, 1-8.

9. HUANG X, ZHENG X, CHEN Z, et al. 2018. Fresh and grilled eel volatile fingerprinting by e-Nose, GC-O, GC-MS and GC $\times$ GC-QTOF combined with purge and trap and solvent-assisted flavor evaporation. Food Research International, 115, 3243.

10. ZHU W H, LUAN H W, BU Y, et al. 2019. Flavor characteristics of shrimp sauces with different fermentation and storage time. LWT - Food Science and Technology, 110, 142-151.

11. HORWITZ W, HORWITZ W, KANE P F, et al. 2005. Official methods of analysis of the AOAC international. Trends in Food Science \& Technology, 6(11), 382-382.

12. TOLDRA F, REIG M. Innovations for healthier processed meats. 2011. Trends in Food Science \& Technology, 22(9), 517-522.

13. HAYAKAWA T, YOSHIDA Y, YASUI M, et al. 2011. Heat-induced gelation of myosin in a low ionic strength solution containing L-histidine. Meat science, 90(1), 77-80.

14. ZHOU C, LI J, and TAN S J. 2014. Effect of Llysine on the physicochemical properties of pork sausage. Food Science \& Biotechnology, 23(3), 775-780. 
15. GUERRERO L, GELABERT J, GOU P, et al. 2008. Sensory characterisation and consumer acceptability of small calibre fermented sausages with $50 \%$ substitution of $\mathrm{NaCl}$ by mixtures of $\mathrm{KCl}$ and potassium lactate. Meat Science, 80, 1225-1230.

16. INGUGLIA E S, ZHANG Z, TIWARI B K, et al. 2016. Salt reduction strategies in processed meat products-A review. Trends in Food Science \&Technology, 59, 70-78.

17. INGUGLIA E S, ZHANG Z, TIWARI B K, et al. 2016. Salt reduction strategies in processed meat products-A review. Trends in Food Science \&Technology, 59, 70-78.

18. BAMPI M, DOMSCHKE N N, SCHMIDT F C, et al. 2016. Influence of vacuum application, acid addition and partial replacement of $\mathrm{NaCl}$ by $\mathrm{KCl}$ on the mass transfer during salting of beef cuts. LWTFood Science and Technology, 74, 26-33.

19. DONG W J, ZHAO J P, HU R S, et al. 2017. Differentiation of chinese robusta coffees according to species, using a combined electronic nose and tongue, with the aid of chemometrics. Food Chemistry, 229, 743-751. 